\title{
A SIMPLE GREEN REDUCTION STRATEGY TO SUBSTITUTE CADMIUM IN ANALYTICAL REDUCTION OF NITRATE IN GRIESS-ILOSVAY METHOD
}

\author{
Alexsandro Antônio Matias ${ }^{\mathrm{a}}$, André Fernando de Oliveira*,a, ${ }^{*}$, Antônio Augusto Neves ${ }^{\mathrm{a}}$ and Maria Eliana Lopes Ribeiro \\ de Queiroz ${ }^{\text {a }}$ \\ aDepartamento de Química, Universidade Federal de Viçosa, 36.570-900 Viçosa - MG, Brasil
}

Recebido em 04/08/2020; aceito em 20/10/2020; publicado na web em 11/11/2020

\begin{abstract}
Nitrate is an abundant ion that is present in many industrialized products and the environment. Various analytical methods have been described using the Griess-Ilosvay reagent for the determination of nitrate in different matrices after its reduction to nitrite, in most cases with metallic cadmium as the reducer. This work proposes a new method using aluminum spheres coated with a copper film for this reduction. To optimize the method, it was important to evaluate the conditions for the deposition of the copper film on the aluminum spheres, using a Doehlert matrix. The optimized method provided an analytical range from 2.0 to $100 \mu \mathrm{mol} \mathrm{L} \mathrm{L}^{-1}$, with a coefficient of determination of 0.9996 and a standard deviation of residuals $\left(\mathrm{s}_{\mathrm{res}}\right)$ of $7.59 \times 10^{-4}$. The Limits of Detection and Quantification were 0.59 and $2.0 \mu \mathrm{mol} \mathrm{L} \mathrm{L}^{-1}$ respectively. The method was applied using mineral water samples and was shown to provide repeatability less than $6.98 \%$ and accuracy obtained through recovery essays between 81.1 and $104.6 \%$ for the determination of nitrate in this type of sample.
\end{abstract}

Keywords: nitrate; aluminum spheres; Griess-Ilosvay reagent; analytical resolution.

\section{INTRODUCTION}

Nitrate $\left(\mathrm{NO}_{3}^{-}\right)$is an abundant anion present in natural or artificial forms in various everyday products. ${ }^{1-7}$ Due to its low reactivity, the nitrate present in wastes generated during the manufacture and use of industrialized products can reach water bodies, ${ }^{8-10}$ where excess nitrate can cause harm to the environment and human health. ${ }^{2,8,11}$ Consequently, nitrate is now considered as an environmental indicator of anthropic pollution. . $^{12,13}$

Various techniques have been described for the quantification of this anion in different environmental matrices, including ion chromatography, ${ }^{14}$ gas chromatography coupled with mass spectrometry, ${ }^{15}$ voltammetry, ${ }^{16}$ infrared spectroscopy, ${ }^{17}$ atomic absorption spectrometry, ${ }^{18}$ and UV-Vis spectroscopy, ${ }^{19,20}$ among others. ${ }^{21}$ Of these, the Griess-Ilosvay spectrophotometric method is one of the techniques most widely used for the determination of nitrate, since it is robust, simple, inexpensive, and selective. ${ }^{21}$ This method is based on the reduction of nitrate to nitrite, with subsequent quantification of nitrite using a diazotization reaction.

The diazotization reaction proposed by Peter Griess ${ }^{22}$ for the synthesis of dyes was modified by Ilosvay ${ }^{23}$ for the determination of nitrate by its reduction with metallic zinc. The nitrite formed is derivatized with 1-naphthylamine and sulfanilic acid, in acetate buffer, forming a diazo compound with a purple color, which absorbs radiation at $540 \mathrm{~nm} .^{24}$

Several methods emerged using the Griess-Ilosvay reagent, such as the procedure described by Mullin and Riley ${ }^{25}$ for the determination of nitrate in seawater, where the reducing agent employed was hydrazine in alkaline medium, in the presence of $\mathrm{Cu}^{2+}$ ions. This method was modified and automated by Kamphake et al. ${ }^{26}$ Later, Downes ${ }^{27}$ showed that the addition of $\mathrm{Zn}^{2+}$ to the reducing solution was able to decrease the interferences in freshwater samples.

Another method for the determination of nitrate was described by Wood et al. ${ }^{28}$ who used a reducing agent consisting of cadmium granules with a surface film of copper (copperized cadmium, $\mathrm{Cd}-\mathrm{Cu}$ ),

*e-mail: andref.oliveira@ufv.br which were packed in a column. This reducer, which has been extensively used in batch and flow methods, is included in the AWWA Standard Methods, as well as in other analytical manuals. ${ }^{11,13,29}$ Among many variations and applications, the method of Tu et al. ${ }^{30}$ can be highlighted, involving the use of a 96-well microplate with 2 granules of $\mathrm{Cd}-\mathrm{Cu}, 250 \mu \mathrm{L}$ of sample, and $50 \mu \mathrm{L}$ of $\mathrm{NH}_{4} \mathrm{Cl}$-EDTA buffer solution ( $\mathrm{pH} 8.5)$ in each well, which provided results comparable to those obtained using a standard column method. ${ }^{30}$

In the methods of Wood et al. and Tu et al., nitrate was reduced to nitrite, followed by the use of the Griess-Ilosvay reagents to quantify nitrite (and consequently nitrate). ${ }^{28,30}$ Despite being satisfactory, these methods employ $\mathrm{Cd}$, which is a toxic element, so it is necessary to identify other agents for the reduction of nitrate to nitrite, eliminating the widely used copperized cadmium column.

The UV radiation was also used for reducing nitrate to nitrite, using flow injection or sequential injection system. ${ }^{31-33}$ Few works have used vanadium(III) as a reducing agent for the determination of nitrate in biological samples, ${ }^{34}$ aqueous samples, ${ }^{35,36}$ and milk. ${ }^{37}$ One disadvantage of V(III) reagent is its toxicity. ${ }^{38,39}$ Still the use of alloys of aluminum with copper, iron, and silicon is effective for the reduction of nitrate, these materials are difficult to obtain, once they are homogeneous solid solutions..$^{40,41}$

The present work proposes a new green method using aluminum spheres coated with a copper film $(\mathrm{Al}-\mathrm{Cu})$ for the reduction of nitrate to nitrite, replacing the use of cadmium or vanadium as reducing agents.

\section{EXPERIMENTAL}

\section{Reagents and solutions}

All solutions were prepared using analytical grade reagents and water obtained from a Milli-Q system (Millipore, Bedford, MA, USA).

Griess-Ilosvay reagent was prepared according to AWWA Standard Methods. ${ }^{29}$ A $25.0 \mathrm{~mL}$ volume of $85 \%$ phosphoric acid (Sigma-Aldrich) was added to $200 \mathrm{~mL}$ of water, together with $2.5 \mathrm{~g}$ 
of sulfanilamide (Vetec, CAS: 63-74-1). After complete dissolution of the sulfanilamide, $0.25 \mathrm{~g}$ of $\mathrm{N}$-(1-naphthyl)-ethylenediamine dihydrochloride (NNED) (Vetec, CAS: 1465-25-4) was added. The solution was quantitatively transferred to a $250 \mathrm{~mL}$ volumetric flask and the volume was completed with water. This solution was stored in an amber flask in a refrigerator, with periodic evaluation of its quality by determining the sensitivity of analytical curves.

Standard solutions of $0.02 \mathrm{~mol} \mathrm{~L}^{-1}$ nitrate $\left(\mathrm{KNO}_{3}\right.$, Vetec, $0.2022 \mathrm{~g} / 100 \mathrm{~mL})$ and $0.10 \mathrm{~mol} \mathrm{~L}-1$ nitrite $\left(\mathrm{NaNO}_{2}\right.$, Vetec, $0.690 \mathrm{~g} / 100 \mathrm{~mL}$ ) were prepared from the salts that had been previously dried in an oven. The nitrate solution was stored in an amber glass flask and was used for a maximum of 6 months. The $0.10 \mathrm{~mol} \mathrm{~L}^{-1}$ nitrite stock solution was prepared and used on the same day. Standard solutions at other concentrations were obtained by appropriate dilutions of the stock solutions.

Solutions of copper (II) in the presence of EDTA were prepared using the salts $\mathrm{CuSO}_{4} .5 \mathrm{H}_{2} \mathrm{O}$ (Vetec) and $\mathrm{Na}_{2} \mathrm{H}_{2}$ EDTA (Vetec, CAS: 6381-92-6). The $\mathrm{pH}$ values of the solutions were adjusted using sodium hydroxide (Vetec) or sulfuric acid (Vetec) at different concentrations.

\section{Procedures}

\section{Formation of the copper film on aluminum metal}

The deposition of the copper film on the aluminum spheres (4.5 mm diameter, 94\% purity, Falcon Armas) was performed in $250 \mathrm{~mL}$ beakers, using $100 \mathrm{~mL} \mathrm{ca}$. of $\mathrm{Cu}^{2+}$-EDTA solution at different concentrations. These spheres are originally sold for airguns. The beakers containing $\mathrm{Cu}^{2+}$-EDTA solution were heated in a microwave oven (Model MEF41, 1600 W, Electrolux) for 1 min at 100\% power, followed by the addition of 18 aluminum spheres that had been previously cleaned in $5.0 \mathrm{~mol} \mathrm{~L}^{-1}$ sulfuric acid for $10 \mathrm{~min}$. Heating was then continued for $25 \mathrm{~min}$ at $10 \%$ power. During this process, the solutions were manually agitated every $5 \mathrm{~min}$. The aluminum spheres coated with copper film $(\mathrm{Al}-\mathrm{Cu})$ were removed and washed with water, before use.

Optimization of the $\mathrm{pH}$ and the copper concentration was performed according to a Doehlert matrix. The influence of time on the deposition of copper on the aluminum spheres was evaluated by heating the solution for periods of 15,25 , and $40 \mathrm{~min}$.

\section{Optimization of deposition of the copper film on the aluminum spheres}

The assays for optimization of deposition of the copper film on the aluminum spheres were performed according to a Doehlert matrix, with the variables considered being (A) the $\mathrm{pH}$ of the solution and (B) the logarithm of the copper(II) concentration $\left(\log \mathrm{c}\left(\mathrm{Cu}^{2+}\right)\right){ }^{42,43}$ Table 1 shows the coded values of the variables for each experimental condition. Three levels were used for the copper (II) concentration (0.001, 0.01, and $\left.0.1 \mathrm{~mol} \mathrm{~L}^{-1}\right)$, with the solutions prepared in media containing EDTA at concentrations 1.5-fold higher than the copper (II) concentrations. The $\mathrm{pH}$ was studied at 5 levels $(8.5,9.0$, 9.5, 10.0, and 10.5).

For each experiment, an analytical curve was obtained using solutions of nitrate at concentrations between 10 and $100 \mu \mathrm{mol} \mathrm{L}{ }^{-1}$ in $0.01 \mathrm{~mol} \mathrm{~L}^{-1} \mathrm{NaOH}$ solution. The responses considered were the curve parameters, including the analytical sensitivity (S), given by the slope of the analytical curve, ${ }^{44,45}$ the number of nines (N9) of the determination coefficient $\left(\mathrm{R}^{2}\right)$, as specified by Andrade et al. ${ }^{46}$ (Equation 1), and the analytical resolution, which is a parameter proposed in this work (Equation 2).

$$
N 9=-\log \left(1-R^{2}\right)
$$

Table 1. Experimental and coded values for the Doehlert matrix experimental design for optimization of copper deposition on the aluminum spheres

\begin{tabular}{cccc}
\hline \multicolumn{2}{c}{ CODED VALUES } & \multicolumn{2}{c}{ EXPERIMENTAL VALUES } \\
\hline $\mathrm{A}$ & $\mathrm{B}$ & $\mathrm{pH}$ & $\log \mathrm{c}\left(\mathrm{Cu}^{2+}\right)$ \\
\hline-1.0 & 0.000 & 8.5 & -2.0 \\
-0.5 & -0.866 & 9.0 & -3.0 \\
-0.5 & 0.866 & 9.0 & -1.0 \\
0.0 & 0.000 & 9.5 & -2.0 \\
0.5 & -0.866 & 10.0 & -3.0 \\
0.5 & 0.866 & 10.0 & -1.0 \\
1.0 & 0.000 & 10.5 & -2.0 \\
0.0 & 0.000 & 9.5 & -2.0 \\
\hline
\end{tabular}

$$
r A=\frac{3 s_{r e s}}{S}
$$

where $\mathrm{S}_{\text {res }}$ is the standard deviation of the residuals and $\mathrm{S}$ is the sensitivity.

For each type of response, a multiple regression model $(\hat{R})$ was obtained, considering the quadratic terms and the first order interactions (Equation 3).42,47

$$
\hat{R}=a A+b B+c A B+d A^{2}+e B^{2}+f
$$

where $\mathrm{R}$ is the response estimated by the model, $\mathrm{A}$ and $\mathrm{B}$ are the independent variables, and the lower case letters are the coefficients of the regression model.

The procedure suggested by Andrade et al. ${ }^{46}$ was used to obtain the most suitable model, eliminating the non-significant terms of the multiple regression model, hence obtaining a new model. Significance was indicated by p-values lower than 0.05 in the Student's t-test $\left(\mathrm{t}_{\text {calc }}\right)$ (Equation 4 ), evaluating each coefficient $\left(\beta_{\mathrm{i}}\right)$ in relation to zero (no influence of the term).

$$
t_{\text {calc }}=\frac{\left|\beta_{i}-0\right|}{s\left(\beta_{i}\right)}
$$

The procedure was performed exhaustively, using different combinations, until only the significant terms were obtained.

\section{Determination of nitrate}

The first step in the procedure was the reduction of nitrate to nitrite, performed by adding $10.0 \mathrm{~mL}$ of a solution of $\mathrm{NO}_{3}^{-}$, at different concentrations, to an $\mathrm{Al}-\mathrm{Cu}$ sphere. This system was kept under agitation for $90 \mathrm{~min}$, at ambient temperature, using a shaker table (Model TE-420, Tecnal) operated at $100 \mathrm{rpm}$. After the reduction step, $0.5 \mathrm{~mL}$ of the Griess-Ilosvay reagent was added to $1.0 \mathrm{~mL}$ of the solution. After a minimum time of $30 \mathrm{~min}$, the absorbance at 540 $\mathrm{nm}$ was measured using a USB2000+ spectrometer (Ocean Optics) coupled to a tungsten halogen lamp (Model HL-2000, Ocean Optics) and a glass cuvette (volume of $700 \mu \mathrm{L}$ and optical path length of $1.0 \mathrm{~cm})$.

\section{Kinetics of reduction of nitrate to nitrite}

Evaluation of the kinetics of reduction of nitrate to nitrite by the $\mathrm{Al}-\mathrm{Cu}$ spheres was performed using different numbers of spheres (from 1 to 5) with copper coatings obtained by microwave heating for $25 \mathrm{~min}$. The tests were performed in quintuplicate, using $10.0 \mathrm{~mL}$ of $400 \mu \mathrm{mol} \mathrm{L}{ }^{-1}$ nitrate solution. Aliquots of $100 \mu \mathrm{L}$ of the solution 
were collected at different times, to which were added $900 \mu \mathrm{L}$ of water and $500 \mu \mathrm{L}$ of Griess-Ilosvay reagent. The spectrophotometric determination of nitrate was performed as described above.

\section{Validation and application of the method}

The figures of merit considered for validation of the optimized method were the limit of detection (LoD), the limit of quantification (LoQ), analytical sensitivity, precision and accuracy (using repeatability and recovery tests), and comparison with the analysis of nitrate in fortified samples using the copperized cadmium method. ${ }^{29}$ The proposed method was applied in the analysis of samples of commercial mineral water purchased in the city of Viçosa (Minas Gerais State, Brazil).

\section{RESULTS AND DISCUSSION}

\section{Deposition of the copper film on the aluminum spheres}

The deposition or presence of metallic copper on the surface of pure aluminum or even its alloy is important due catalytic effect of copper(I). The low soluble copper (I) oxide is naturally formed due to the oxidation of metallic copper in contact with the solution.

During the tests of the deposition of the copper film on the aluminum spheres, the temperature of the $\mathrm{Cu}^{2+}$-EDTA solution (at the different concentrations) was around $87.7 \pm 1.2{ }^{\circ} \mathrm{C}$ after preheating for $1 \mathrm{~min}$ at $100 \%$ power. A temperature of around $91.5 \pm 0.7{ }^{\circ} \mathrm{C}$ was obtained after heating for $25 \mathrm{~min}$ at $10 \%$ power.

The effects of the concentration of the copper (II) solution and the $\mathrm{pH}$ of the medium on the quality of the copper film on the aluminum spheres were investigated using a Doehlert matrix. The results are shown in Table 2.

Application of the multiple regression model (Equation 3) for evaluation of the effects of the variables, considering the analytical sensitivities obtained in the Doehlert matrix experiments, showed that only the logarithm of the copper(II) concentration had a significant influence (Equation 5).

The model presented $\mathrm{R}^{2}$ of 0.9232 (N9 of 1.1) and standard deviation of the residuals of $0.47 \mathrm{~L} \mathrm{nmol}^{-1}$, indicative of a good fit to the experimental data.

$$
S=(2.130 \pm 0.251) B^{2}-(1.738 \pm 0.217) B
$$

where $\mathrm{B}$ represents the coded values for the logarithm of the $\mathrm{Cu}$ (II) concentration.

The use of low concentrations of copper(II) favored higher sensitivity (Figure 1), suggesting the formation of a film with characteristics different from those obtained using higher concentrations, due to slower kinetics of the process. The initial hypothesis of the influence of copper(II) according to first order kinetics was reasonable, justifying selection of the logarithm of the copper(II) concentration.

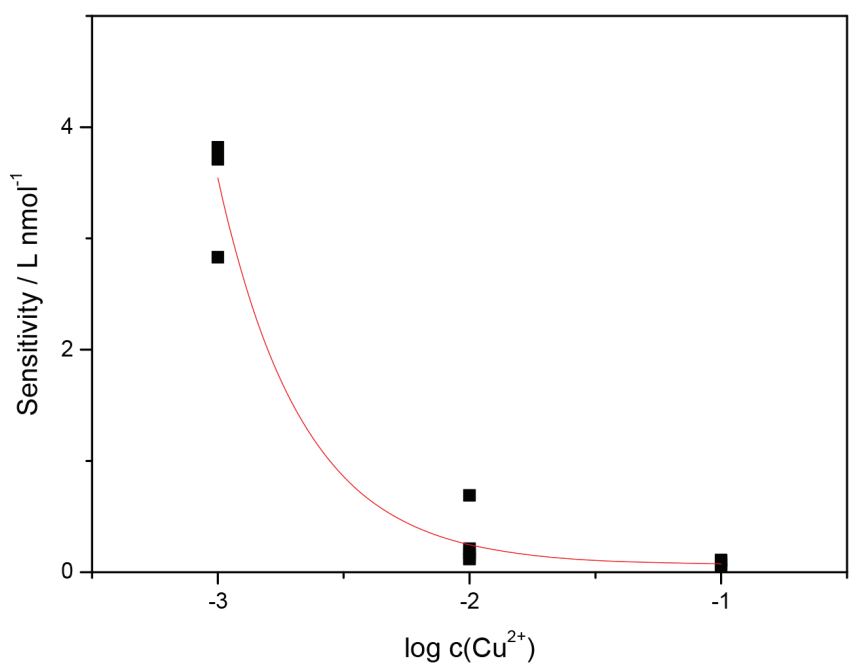

Figure 1. Correlation between sensitivity and $\log c\left(\mathrm{Cu}^{2+}\right)$, according to the Doehlert matrix experiments

It should be highlighted that over $99.98 \%$ of the copper(II) remained complexed by EDTA, favoring a more homogeneous reduction process on the aluminum.

It was not possible to obtain a fitted model for the determination coefficient with a confidence level greater than $95 \%$, considering the two variables studied. The same was found for the N9 parameter, which is a mathematical expression for counting the number of nines in the $\mathrm{R}^{2}$ value, enabling graphical differentiation of determination coefficients $0.9,0.99,0.999$, and so on, since only values higher than 0.9 or 0.99 are considered for analytical curves. ${ }^{48}$

The multiple linear regression model obtained presented $\mathrm{R}_{\text {fitted }}^{2}$ of

Table 2. Parameters of the analytical curves obtained in the assays of the experimental design

\begin{tabular}{|c|c|c|c|c|c|}
\hline \multirow{2}{*}{ Number $^{\mathrm{a}}$} & \multicolumn{2}{|c|}{ Variables } & \multicolumn{3}{|c|}{ Parameters of the analytical curves } \\
\hline & $\mathrm{pH}$ & $\log \mathrm{c}\left(\mathrm{Cu}^{2+}\right)^{\mathrm{b}}$ & Sensitivity / $\left(\mathrm{L} \mathrm{nmol}^{-1}\right)$ & N9 & $\mathrm{rA}^{\mathrm{c}} /\left(\mu \mathrm{mol} \mathrm{L} \mathrm{L}^{-1}\right)$ \\
\hline 1 & 8.50 & -2.0 & 0.12 & 0.72 & 53.9 \\
\hline 1 ' & 8.54 & -2.0 & 0.69 & 0.56 & 67.3 \\
\hline 2 & 9.01 & -3.0 & 3.82 & 2.01 & 11.2 \\
\hline 2 ' & 9.03 & -3.0 & 3.82 & 2.79 & 4.7 \\
\hline 3 & 9.00 & -1.0 & 0.10 & 0.45 & 83.0 \\
\hline $3^{\prime}$ & 9.00 & -1.0 & 0.11 & 0.59 & 62.7 \\
\hline 4 & 9.53 & -2.0 & 0.18 & 0.99 & 37.0 \\
\hline 4 ' & 9.55 & -2.0 & 0.21 & 1.31 & 24.6 \\
\hline 5 & 10.00 & -3.0 & 2.83 & 0.99 & 37.9 \\
\hline 5 & 10.03 & -3.0 & 3.71 & 2.06 & 10.2 \\
\hline 6 & 9.99 & -1.0 & 0.02 & 0.06 & 296.7 \\
\hline $6^{\prime}$ & 10.02 & -1.0 & 0.07 & 0.44 & 82.7 \\
\hline 7 & 10.51 & -2.0 & 0.12 & 0.69 & 54.6 \\
\hline 7 & 10.51 & -2.0 & 0.16 & 0.78 & 48.1 \\
\hline
\end{tabular}

${ }^{\mathrm{a}}$ name of each experiment; ${ }^{\mathrm{b}} \mathrm{mol} \mathrm{L}{ }^{-1} ;{ }^{\mathrm{c}}$ analytical resolution. 
0.8745 (N9 of 0.9) and residual standard deviation of $17.9 \mathrm{~L} \mathrm{nmol}^{-1}$ (Equation 6). Experiment 6 was considered an outlier, as shown by the analysis of the residuals.

$$
\begin{gathered}
r A=(42.504 \pm 9.611) B^{2}+(56.224 \pm 9.029) A^{2}- \\
(34.433 \pm 7.896) B
\end{gathered}
$$

where $\mathrm{A}$ and $\mathrm{B}$ are the coded values for $\mathrm{pH}$ and the logarithm of the $\mathrm{Cu}$ (II) concentration, respectively.

A difficulty in using the analytical sensitivity for selection of the optimal conditions for a method is that it must be considered together with the estimated standard deviation of the measurements or the residuals since the precision of a method is a very important parameter for its optimization. The standard deviation of the residuals is an excellent parameter for evaluating the quality of the fit since it is not relative (as in the case of $\mathrm{R}^{2}$ ) but instead considers the actual analytical response, in this case, the absorbance.

Meanwhile, the analytical resolution (rA) parameter considers these two parameters (the analytical sensitivity and the standard deviation of the residuals), providing an estimate of the smallest difference between two different concentrations, which is ultimately the goal in analytical methods.

The influence of this parameter on the resolution (Figure 2) was also associated with the formation of a more homogeneous film, favoring the repeatability of the data and consequently reducing the standard deviation of the residuals, which is related to the quality of the data used to obtain the analytical curve.

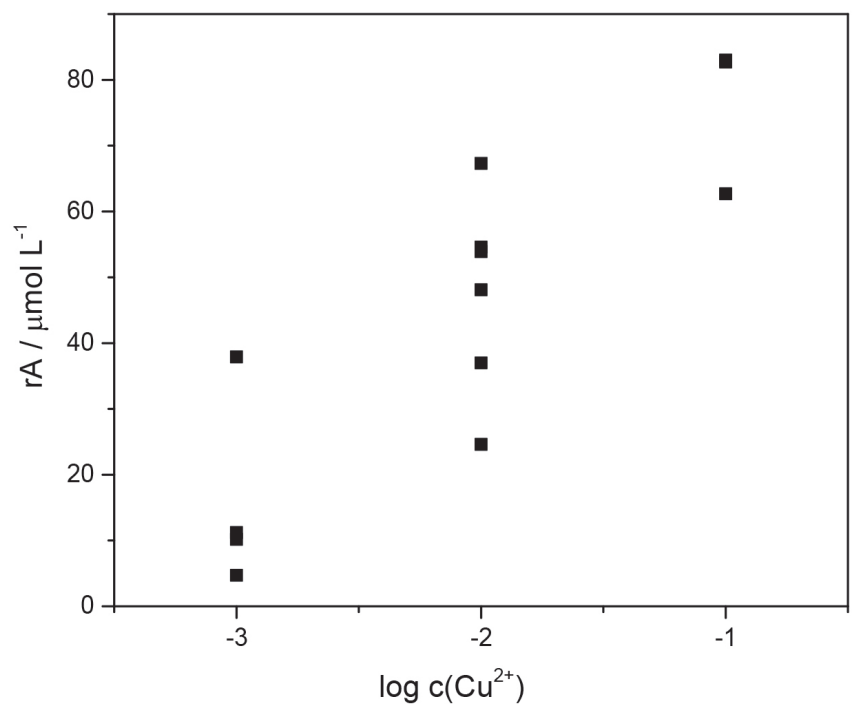

Figure 2. Correlation between the values of $r A$ (analytical resolution) and $\log \mathrm{c}\left(\mathrm{Cu}^{2+}\right)$, obtained in the Doehlert matrix experiments using several different spheres

The data obtained (within the range studied) showed that the best experimental condition was the use of $1 \mathrm{mmol} \mathrm{L}^{-1}$ copper(II) and 1.5 mmol L-1 EDTA, at $\mathrm{pH} 9.0$, which provided the best quality of the analytical curve (considering $\mathrm{R}^{2}$ and the standard deviation of the residuals). Therefore, this condition was selected in the subsequent experiments.

\section{Influence of the time used for deposition of copper on the aluminum spheres}

The influence of the time used for the formation of the copper film on the aluminum spheres was evaluated using the parameters of the analytical curve for nitrate determination (Figure 3). The copper film deposition time was found to influence the sensitivity of the analytical curve, with the highest sensitivity obtained using a deposition time of $25 \mathrm{~min}$, resulting in an analytical resolution of $0.48 \mu \mathrm{mol} \mathrm{L} \mathrm{L}^{-1}$.

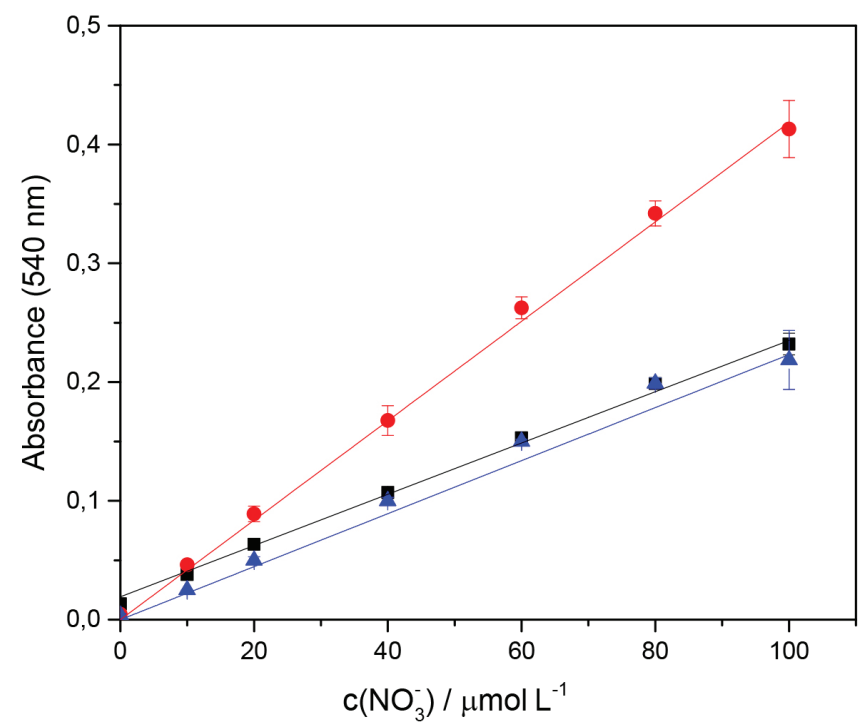

Figure 3. Analytical curves obtained using the spheres with copper

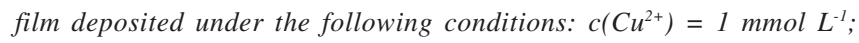
$c(E D T A)=1.5 \mathrm{mmol} \mathrm{L}^{-1} ; p H=9.0$; deposition times of $15(\mathbf{\square}), 25(\mathbf{O})$, and 40 (- $\mathbf{\Delta}$ ) min. The time for reaction of the Al-Cu spheres with nitrate was $90 \mathrm{~min}$. Each solution had one different sphere

Hou et al..$^{41}$ observed that a greater quantity of copper deposited on the surface of an Al-Fe alloy resulted in a faster reduction of nitrate to nitrite, as well as to other products such as ammonium. ${ }^{41}$ This showed the need to employ suitable experimental conditions, with the film formed favoring the formation of nitrite, rather than other products.

\section{Influence of the number of aluminum spheres}

The kinetic behavior of the reduction of nitrate to nitrite was evaluated using different numbers of spheres (Figure 4).

The increase of the number of spheres (and consequently the available surface area) resulted in a faster rate of nitrite formation,

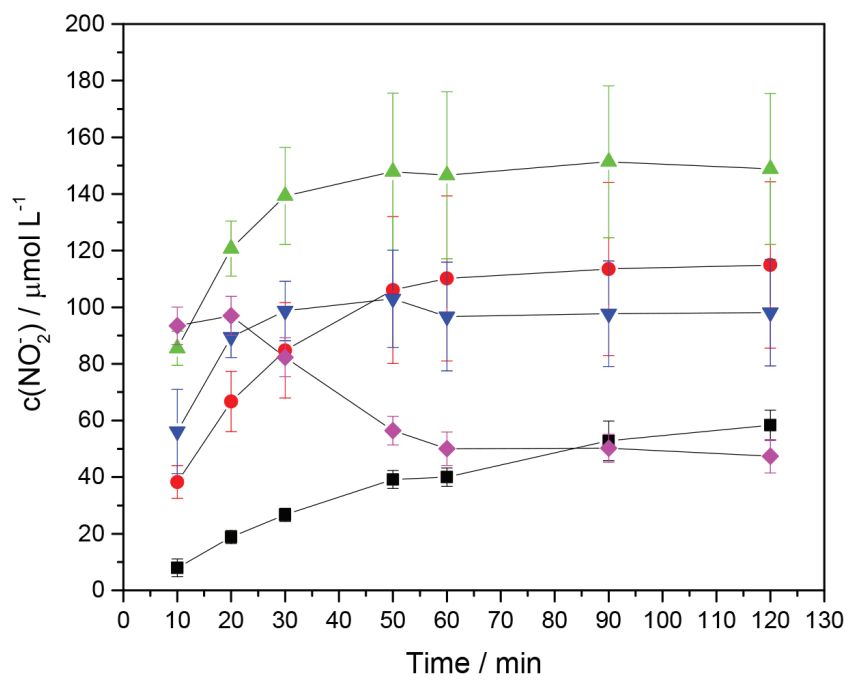

Figure 4. Kinetic behavior of the formation of nitrite by reduction of nitrate in $10 \mathrm{~mL}$ of a solution of $400 \mu \mathrm{mol} \mathrm{L} \mathrm{L}^{-1}$ nitrate in $10 \mathrm{mmol} \mathrm{L^{-1 }} \mathrm{NaOH}$, using different numbers of aluminum spheres: $1(\mathbf{\square}), 2(\bullet), 3(\Delta), 4(\nabla), 5(\diamond)$ 
for the same amount of nitrate, but also in the formation of species with smaller oxidation numbers (such as $\mathrm{N}_{2}$ or $\mathrm{NH}_{4}^{+}$).

When four or more spheres were used, it could be seen that there was a competition between the two mechanisms. Besides, as the number of spheres was increased up to four spheres, the relative standard deviations (\% RSD) became higher, indicating that there was poorer repeatability of the results (Figure 5).

The role of copper in the aluminum sphere seems associated with a synergic effect of the catalytic action of copper(I) fastly formed on metallic copper film and the high reducing effect of metallic aluminum, restoring the copper(I). This effect seems to occur also in cadmium particles. The surface of aluminum alone (as cadmium) has a catalytic effect too, once the reduction occurs in absence of copper film, but less efficient. And the reduction is not only due to the favorable electric potentials, once another metallic surface of other convenient metal, the reduction to nitrite, not occurs.

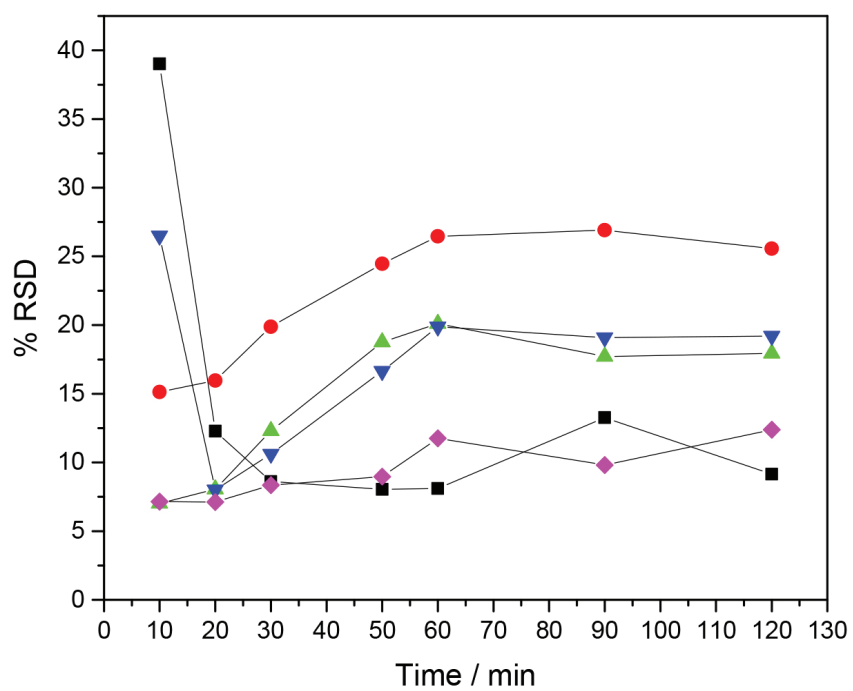

Figure 5. The behavior of the relative standard deviations in the kinetics of formation of nitrite by reduction of nitrate in $10 \mathrm{~mL}$ of a $400 \mu \mathrm{mol} \mathrm{L} \mathrm{L}^{-1}$ solution of nitrate in $10 \mathrm{mmol} \mathrm{L}^{-1} \mathrm{NaOH}$, according to the number of aluminum spheres: $1(\square), 2(\mathbf{O}), 3(\Delta), 4(\mathbf{\nabla}), 5(\diamond)$

Therefore, it was decided to use only one sphere, in order to achieve the best analytical resolution, representing the condition that provided the best repeatability, despite lower sensitivity.

\section{Validation and application of the method}

Figure 6 shows the analytical curve for the determination of nitrate by the proposed method. The curve was constructed using the results of analyses performed under the optimized conditions.

The heteroscedasticity of the data for the analytical curve shown in Figure 6 was confirmed by the correlation $\left(R^{2}=0.94\right)$ between the standard deviation of the absorbance at each point and the nitrate standard concentrations (Figure 7).

Hence, a weighted linear regression model was used, rather than an ordinary model,${ }^{49}$ without considering the constant term (blank), since it was not considered significantly different from zero. The model obtained is shown in Equation 7.

$$
\hat{\mathrm{A}}=(3.88 \pm 0.03) \times 10^{-3} c\left(\mathrm{NO}_{3}^{-}\right)
$$

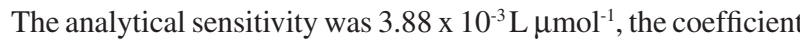
of determination $\left(\mathrm{R}^{2}\right)$ was 0.9996 (N9 of 3.4), and the standard deviation of the residuals $\left(\mathrm{s}_{\mathrm{res}}\right)$ was $7.59 \times 10^{-4}$. All the parameters

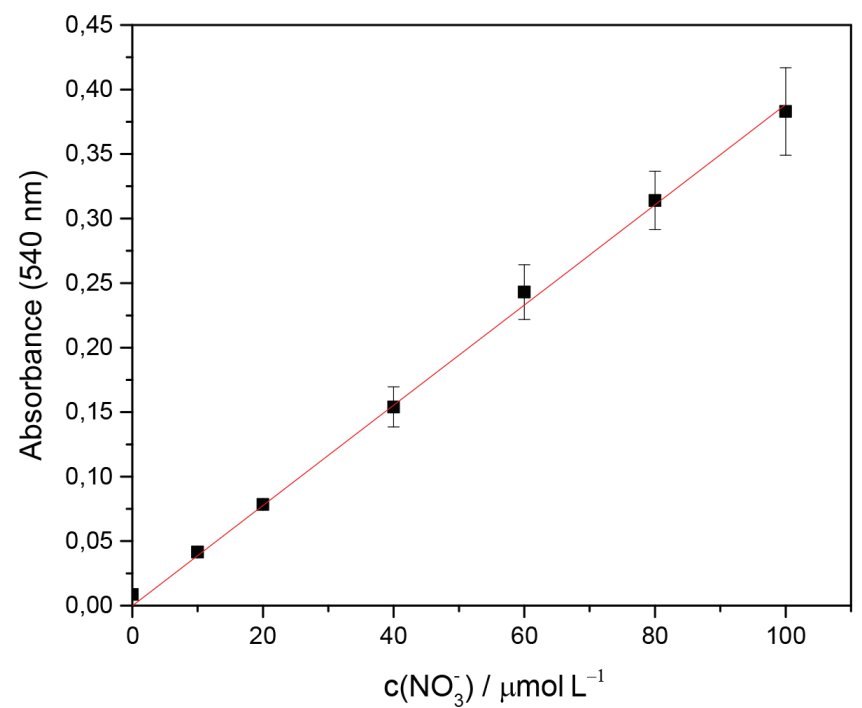

Figure 6. The analytical curve for the determination of nitrate using the $\mathrm{Al}-\mathrm{Cu}$

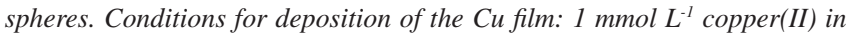
1.5 mmol $L^{-1}$ EDTA, at pH 9.0, with deposition time of $25 \mathrm{~min}$. Conditions for the reduction of nitrate: one $\mathrm{Al}$-Cu sphere in $10 \mathrm{~mL}$ of a solution of nitrate in $10 \mathrm{mmol} \mathrm{L} \mathrm{L}^{-1} \mathrm{NaOH}$, with agitation at $100 \mathrm{rpm}$ and reaction time of $90 \mathrm{~min}$. The linear equation is shown in Equation 7

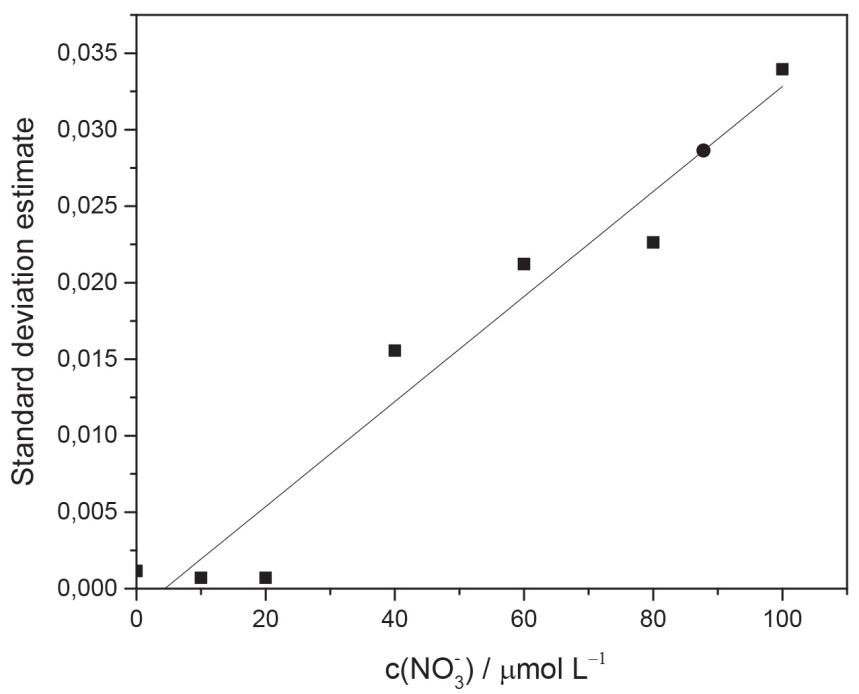

Figure 7. Heteroscedasticity of the standard deviations for each point of the analytical curve. Conditions for deposition of the Cu film: $1 \mathrm{mmol} \mathrm{L^{-1 }}$ copper(II) in $1.5 \mathrm{mmol} \mathrm{L} \mathrm{L}^{-1}$ EDTA, at pH 9.0, with deposition time of $25 \mathrm{~min}$. Conditions for the reduction of nitrate: one Al-Cu sphere in $10 \mathrm{~mL}$ of a solution of nitrate in $10 \mathrm{mmol} \mathrm{L} \mathrm{L}^{-1} \mathrm{NaOH}$, with agitation at $100 \mathrm{rpm}$ and reaction time of $90 \mathrm{~min}$

showed the good fit of the analytical curve model, including the analytical resolution (rA) value of $0.59 \mu \mathrm{mol} \mathrm{L}^{-1}$.

The limits of detection (LoD) and quantification (LoQ) were calculated using the standard deviation of the residuals, with values of 0.59 and $2.0 \mu \mathrm{mol} \mathrm{L} \mathrm{L}^{-1}$ obtained, respectively, calculated as 3 and 10 times the standard deviation of the residuals, ignoring the blank term. Therefore, the LoD could be considered to be the same as the analytical resolution of the method.

The linear range of the method was from 2.0 to $100.0 \mu \mathrm{mol} \mathrm{L}-1$ (0.03 to $2,8 \mathrm{mg} \mathrm{L}^{-1} \mathrm{~N}$ ), which was comparable to the range for the traditional method $\left(0.7-71.4 \mu \mathrm{mol} \mathrm{L} \mathrm{L}^{-1}\right) .{ }^{29}$ These values are less than the maximum concentration in regulatory legislations (about $\left.10 \mathrm{mg} \mathrm{L}^{-1} \mathrm{~N}\right) .^{50}$ 
The precision of the method was determined in repeatability tests employing seven measurements at nitrate concentrations of 0 , 4, 20, and $80 \mu \mathrm{mol} \mathrm{L}{ }^{-1}$. The relative standard deviations (\% RSD) obtained were $6.36,4.08,3.26$, and $6.98 \%$, respectively, which could be considered acceptable.

The accuracy of the method was evaluated using addition and recovery tests performed with four mineral water samples, each containing nitrate at concentrations of 20,40 , and $80 \mu \mathrm{mol} \mathrm{L} \mathrm{L}^{-1}$. The values obtained (Table 3 ) were within the range considered acceptable. $^{48}$

Table 3. Percentage recoveries obtained for analyses of nitrate in mineral water samples

\begin{tabular}{ccc}
\hline Sample & $\begin{array}{c}\text { Concentration added } \\
\left(\mu \mathrm{mol} \mathrm{L} \mathrm{L}^{-1}\right)\end{array}$ & $\begin{array}{c}\text { \% Recovery } \\
\left(\% \text { rec. }^{\mathrm{a}} \pm \mathrm{s}_{\mathrm{rec}}{ }^{\mathrm{b}}\right)\end{array}$ \\
\hline \multirow{2}{*}{1} & 20.0 & $101.2 \pm 4.1$ \\
& 40.0 & $100.3 \pm 4.4$ \\
& 80.0 & $81.1 \pm 0.5$ \\
\hline \multirow{2}{*}{2} & 20.0 & $90.5 \pm 2.2$ \\
& 40.0 & $94.8 \pm 2.0$ \\
& 80.0 & $84.2 \pm 4.0$ \\
\hline \multirow{2}{*}{3} & 20.0 & $104.6 \pm 5.8$ \\
& 40.0 & $100.0 \pm 1.1$ \\
& 80.0 & $110.3 \pm 2.4$ \\
\hline & 20.0 & $95.6 \pm 2.1$ \\
& 40.0 & $102.8 \pm 1.0$ \\
& 80.0 & $84.2 \pm 1.4$ \\
\hline
\end{tabular}

a \%rec.: percentage recovery; ${ }^{\mathrm{b}} \mathrm{s}_{\mathrm{rec}}$ : standard deviation of the percentage recovery $(n=3)$.

The proposed method was also compared with the classical cadmium column technique, applying both methods to two samples of mineral water fortified by the addition of a nitrate standard to give a final nitrate concentration of $40.0 \mu \mathrm{mol} \mathrm{L}{ }^{-1}$. The results of this comparison are provided in Table 4.

The results showed that the values obtained using the proposed method were not significantly different (Student's t-test, 95\% confidence) from those obtained using the cadmium column reference method.
Table 4. Determination of nitrate in mineral water samples fortified with nitrate to give a final concentration of $40 \mu \mathrm{mol} \mathrm{L}^{-1}(\mathrm{n}=3)$, employing the proposed and reference methods

\begin{tabular}{cccc}
\hline \multirow{2}{*}{ Sample } & \multicolumn{2}{c}{$\mathrm{c}\left(\mathrm{NO}_{3}{ }^{-}\right)\left(\mu \mathrm{mol} \mathrm{L} \mathrm{L}^{-1}\right)$} & \multirow{2}{*}{$\%$ error } \\
\cline { 2 - 3 } & Proposed method & Reference method & \\
\hline 1 & $39.95 \pm 0.93$ & $38.94 \pm 0.14$ & 2.52 \\
2 & $41.75 \pm 2.29$ & $39.14 \pm 0.29$ & 6.25 \\
\hline
\end{tabular}

To determine whether the proposed method was influenced by matrix effects, it was applied to six samples of mineral water, with both direct quantification (employing an analytical curve constructed using standards in ultrapure water) and quantification according to the standard additions procedure. Table 5 shows the results of the tests performed in triplicate.

The two methods were not significantly different, according to the Student's t-test for paired means (95\% confidence level), demonstrating that the proposed method was not influenced by matrix effects in the analysis of mineral water samples.

About the time of reaction, the method using a column has a long time to pass the solution through the cadmium column, one by time. The advantage of the proposed method is the possibility of the use of several samples procedure in parallel. The only one-use sphere is not a problem in this proposed method once the formation of the film is easy and there is not a use of columns. In this way, the analytical frequency could be higher than for methods with a cadmium column.

\section{CONCLUSIONS}

This work investigated the feasibility of eliminating the use of cadmium or vanadium for the reduction of nitrate to nitrite, instead of using spectrophotometric determination of nitrite after reduction of nitrate with aluminum spheres coated with a copper film. Validation of the method resulted in figures of merit similar to those for other methods reported in the literature. The findings highlight the suitability of copper redox systems for the reduction of nitrate.

\section{ACKNOWLEDGEMENTS}

The authors are grateful for the financial support of this research provided by Conselho Nacional de Pesquisa (CNPq) and Fundação de Amparo a Pesquisa do Estado de Minas Gerais (FAPEMIG).

Table 5. Determination of nitrate in samples of mineral water using the proposed method

\begin{tabular}{cccc}
\hline Sample & Direct determination $(\mathrm{DD})\left(\mathrm{n}^{\mathrm{a}}=3\right)$ & Determination using standard additions $(\mathrm{DSA})(\mathrm{n}=6)$ & $\mathrm{Error}{ }^{\mathrm{b}}(\%)$ \\
\hline 1 & $\left.\mathrm{c}\left(\mathrm{NO}_{3}^{-}\right)(\mu \mathrm{mol} \mathrm{L})^{-1}\right)$ & $\mathrm{c}\left(\mathrm{NO}_{3}^{-}\right)\left(\mu \mathrm{mol} \mathrm{L}^{-1}\right)$ & $167.89 \pm 0.48$ \\
2 & $170.05 \pm 5.70$ & $5.02 \pm 0.04$ & 1 \\
3 & $5.58 \pm 0.28$ & $34.79 \pm 0.09$ & -12 \\
4 & $30.62 \pm 2.41$ & $4.57 \pm 0.08$ & 28 \\
5 & $5.90 \pm 0.96$ & $32.82 \pm 0.47$ & -9 \\
6 & $29.98 \pm 1.46$ & $7.60 \pm 0.09$ & 30 \\
\hline
\end{tabular}

${ }^{\mathrm{a}} \mathrm{n}$ : number of replicates; ${ }^{\mathrm{b}}$ Error $=(\mathrm{DD}-\mathrm{DSA}) /(\mathrm{DSA})$.

\section{REFERENCES}

1. Kalaycioğlu, Z.; Erim, F. B.; J. Agric. Food Chem. 2019, 67, 7205.

2. Chetty, A. A.; Prasad, S.; Food Chem. 2016, 197, 503.

3. Bahadoran, Z.; Mirmiran, P.; Jeddi, S.; Azizi, F.; Ghasemi, A.; Hadaegh,
F.; J. Food Compos. Anal. 2016, 51, 93.

4. Cumpstey, A. F.; Hennis, P. J.; Gilbert-Kawai, E. T.; Fernandez, B. O.; Grant, D.; Jenner, W.; Poudevigne, M.; Moyses, H.; Levett, D. Z.; Cobb, A.; Meale, P.; Mitchell, K.; Pöhnl, H.; Mythen, M. G.; Grocott, M. P.; Martin, D. S.; Feelisch, M.; Nitric Oxide 2020, 94, 27. 
5. Münzel, T.; Daiber, A.; Vascul. Pharmacol. 2018, 102, 1.

6. Rashid, G.; Avais, M.; Ahmad, S. S.; Mushtaq, M. H.; Ahmed, R.; Ali, M.; Haque, M. N.; Ahmad, M.; Khan, M. A.; Khan, N. U.; Pak. J. Zool. 2019, 51, 249.

7. Zheng, J.; Qu, Y.; Kilasara, M. M.; Mmari, W. N.; Funakawa, S.; Soil Tillage Res. 2019, 194, 104295.

8. Zhang, Y.; Li, F.; Zhang, Q.; Li, J.; Liu, Q.; Sci. Total Environ. 2014, 490, 213.

9. Perović, M.; Obradović, V.; Kovačević, S.; Mitrinović, D.; Živančev, N.; Nenin, T.; Water Environ. Res. 2017, 89, 4.

10. Burow, K. R.; Nolan, B. T.; Rupert, M. G.; Dubrovsky, N. M.; Environ. Sci. Technol. 2010, 44, 4988.

11. Alahi, M. E. E.; Mukhopadhyay, S. C.; Sens. Actuators, A 2018, 280, 210.

12. Sah, R. N.; Commun. Soil Sci. Plant Anal. 1994, 25, 2841.

13. Singh, P.; Singh, M. K.; Beg, Y. R.; Nishad, G. R.; Talanta 2019, 191, 364.

14. Ito, K.; Takayama, Y.; Makabe, N.; Mitsui, R.; Hirokawa, T.; J. Chromatogr. A 2005, 1083, 63.

15. Campanella, B.; Onor, M.; Pagliano, E.; Anal. Chim. Acta 2017, 980, 33.

16. Massah, J.; Asefpour Vakilian, K.; Biosyst. Eng. 2019, 177, 49.

17. Du, X.; Ye, S.; Dong, D.; J. Food Process Eng. 2019, 42.

18. Roohparvar, R.; Shamspur, T.; Mostafavi, A.; Bagheri, H.; Microchem. J. 2018, 142, 135.

19. Causse, J.; Thomas, O.; Jung, A.-V.; Thomas, M.-F.; Water Res. 2017, 108, 312.

20. Valiente, N.; Gómez-Alday, J. J.; Jirsa, F.; Microchem. J. 2019, 145, 951.

21. Wang, Q.-H.; Yu, L.-J.; Liu, Y.; Lin, L.; Lu, R.; Zhu, J.; He, L.; Lu, Z.-L.; Talanta 2017, 165, 709.

22. Griess, P.; Ber. Dtsch. Chem. Ges. 1879, 12, 426.

23. Ilosvay, M. L.; Bulletin de la Société chimique de Paris 1889, 2, 347.

24. Ivanov, V. M.; J. Anal. Chem. 2004, 59, 1002.

25. Mullin, J. B.; Riley, J. P.; Anal. Chim. Acta 1955, 12, 464.

26. Kamphake, L. J.; Hannah, S. A.; Cohen, J. M.; Water Res. 1967, 1, 205

27. Downes, M. T.; Water Res. 1978, 12, 673.

28. Wood, E. D.; Armstrong, F. A. J.; Richards, F. A.; J. Mar. Biol. Assoc. United Kingdom 1967, 47, 23.
29. APHA-AWWA-WEF In Standard Methods for the Examination of Water and Wastewater; Clesceri, L. S., Greenberg, A. E., Eaton, A. D., eds.; $20^{\text {th }}$ ed.; American Public Health Association: Washington, DC, 1998.

30. Tu, X.; Xiao, B.; Xiong, J.; Chen, X.; Talanta 2010, 82, 976.

31. Takeda, K.; Fujiwara, K.; Anal. Chim. Acta 1993, 276, 25.

32. Motomizu, S.; Sanada, M.; Anal. Chim. Acta 1995, 308, 406.

33. Machado, A.; Marshall, G.; Bordalo, A. A.; Mesquita, R. B. R.; Anal. Methods 2017, 9, 1876.

34. Miranda, K. M.; Espey, M. G.; Wink, D. A.; Nitric Oxide 2001, 5, 62.

35. Wang, S.; Lin, K.; Chen, N.; Yuan, D.; Ma, J.; Talanta 2016, 146, 744.

36. Lin, K.; Li, P.; Ma, J.; Yuan, D.; Talanta 2019, 195, 613.

37. Woollard, D. C.; Indyk, H. E.; Int. Dairy J. 2014, 35, 88.

38. Nedrich, S. M.; Chappaz, A.; Hudson, M. L.; Brown, S. S.; Burton, G. A.; Sci. Total Environ. 2018, 612, 313.

39. Chen, D.; Xiao, Z.; Wang, H.; Yang, K.; Bioresour. Technol. 2018, 264 , 319.

40. Bao, Z.; Hu, Q.; Qi, W.; Tang, Y.; Wang, W.; Wan, P.; Chao, J.; Yang, X. J.; J. Environ. Manage. 2017, 196, 666.

41. Hou, M.; Tang, Y.; Xu, J.; Pu, Y.; Lin, A.; Zhang, L.; Xiong, J.; Yang, X. J.; Wan, P.; J. Environ. Chem. Eng. 2015, 3, 2401.

42. Ferreira, S. L. C.; dos Santos, W. N. .; Quintella, C. M.; Neto, B. B.; Bosque-Sendra, J. M.; Talanta 2004, 63, 1061.

43. Doehlert, D. H.; Appl. Stat. 1970, 19, 231.

44. Currie, L. A.; Pure Appl. Chem. 1995, 67, 1699.

45. IUPAC; Compendium of Chemical Terminology, 2nd ed. (the "Gold Book”), Compiled by A. D. McNaught and A. Wilkinson, Online version, Blackwell Scientific Publications: Oxford, 1997.

46. Andrade, C. E. O.; Oliveira, A. F.; Neves, A. A.; Queiroz, M. E. L. R.; Spectrochim. Acta, Part A2016, 168, 253

47. Araujo, P. W.; Brereton, R. G.; Trends Anal. Chem. 1996, 15, 63.

48. Agencia Nacional de Vigilância Sanitária (ANVISA); Resolução RDC $N^{o}$ 166, de 24 de julho de 2017; Diário Oficial da União: Brasília, Brasil, 2017.

49. Draper, N. R.; Smith, H. Applied Regression Analysis, Vol. 87, $3^{\text {rd }}$ ed., Wiley: New York, 1998.

50. Ward, M. H.; Jones, R. R.; Brender, J. D.; Kok, T. M; Weyer, P. J.; Nolan, B. T.; Villanueva, C. M.; van Breda, S. G.; Int. J. Environ. Res. Public Health. 2018, 15, 1557. 